\title{
Desorption Chemical Ionization Tandem Mass Spectrometry of Polyprenyl and Dolichyl Phosphates
}

\author{
Beata A. Wolucka, Raoul Rozenberg, and Edmond de Hoffmann \\ Department of Chemistry, University of Louvain, Louvain-la-Neuve, Belgium
}

Tadeusz Chojnacki

Institute of Biochemistry and Biophysics, Polish Academy of Sciences, Warsaw, Poland

\begin{abstract}
Negative-ion desorption chemical ionization (DCI) tandem mass spectrometry was applied to the analysis of nanomole quantities of semisynthetic polyisoprenyl phosphates, the chain length of which ranged from 7 to 20 isoprene units. The DCI spectrum of all the compounds tested show the presence of independently generated ions $\left[\mathrm{M}-\mathrm{HPO}_{3}-\mathrm{H}\right]^{-},\left[\mathrm{M}-\mathrm{H}_{3} \mathrm{PO}_{2}\right.$ $-\mathrm{H}]^{-}$and $\left[\mathrm{M}-\mathrm{H}_{3} \mathrm{PO}_{4}-\mathrm{H}\right]^{-}$resulting from the loss of a part of or the entire phosphate group of a polyisoprenyl-P. In tandem mass spectrometry, the $\left[\mathrm{M}-\mathrm{H}_{3} \mathrm{PO}_{4}-\mathrm{H}\right]^{-}$fragment produces series of ions 68 mass units apart, indicative of the polyisoprenoid nature of a compound. Studies with deuterated and $\alpha$-saturated polyisoprenyl phosphates demonstrated that fragmentations of the $\left[\mathrm{M}-\mathrm{H}_{3} \mathrm{PO}_{4}-\mathrm{H}\right]^{-}$ion proceed from both ends $(\alpha$ and $\omega)$ of a polyisoprenoid chain and may occur at either allylic (A) or vinylic (V) sites. Fragments of masses equal to $[n \times 68-1]$ and $[n \times 68-13$ ] (where $n$ is the number of isoprene units and $3 \leq n$ is less than the total number of isoprene residues within a polyisoprenoid chain) comprise the $\alpha \mathrm{A}$ and $\omega \mathrm{V}$ series, respectively, and represent the most abundant ions in tandem mass spectra of the $\left[\mathrm{M}-\mathrm{H}_{3} \mathrm{PO}_{4}-\mathrm{H}\right]^{-}$fragment of polyprenyl phosphates. $\alpha-$ Saturated dolichyl phosphates can be distinguished easily from corresponding polyprenyl phosphates not only on the basis of a 2-u shift of the $\left[\mathrm{M}-\mathrm{H}_{3} \mathrm{PO}_{4}-\mathrm{H}\right]^{-}$ion and the $\alpha$ series of fragments, but also because of the presence of an additional $(A+14)$ series of ions $14 \mathrm{u}$ heavier than fragments resulting from the allylic cleavages of an $\alpha$-saturated polyisoprenoid chain. Possible mechanisms of the collision-induced dissociation reactions of polyprenyl phosphates are discussed. (J Am Soc Mass Spectrom 1996, 7, 958-964)
\end{abstract}

$\mathrm{T}$ The phosphate esters of polyisoprenoid alcohols (Scheme I) can be divided into two classes of biochemically distinct compounds-dolichyl and polyprenyl phosphates-dependent on the presence of a saturation in the $\alpha$-isoprene residue (adjacent to the hydroxyl group) [1]. In polyprenyl derivatives, the $\alpha$-isoprene unit is unsaturated (Scheme Ia), whereas in dolichyl compounds, it is saturated (Scheme Ib). Other structural variations are found within each of the two classes of naturally occurring polyisoprenyl phosphates, such as the number of isoprene units, the cis/trans geometry, and the presence of saturations and other modifications at the $\omega$ end of a polyisoprenoid chain. The structural features of polyisoprenyl phosphates seem to be specific for the biological origin and function of a compound. It is generally accepted that dolichyl and polyprenyl phosphates are interme-

Address reprint requests and correspondence to Professor Beata A. Wolucka, Department of Chemistry, University of Louvain, Place Louis Pasteur 1/1B, B-1348 Louvain-la-Neuve, Belgium. diates for the biosynthesis of glycoconjugates and that, in the first step, they serve as acceptors of glycosyl or glycosyl phosphate moieties from glycosyl esters of nucleoside pyro- (or mono-) phosphates.

Long-chain $\left(\mathrm{C}_{90-100}\right)$ dolichyl phosphates are present in higher eukaryotes, both animals [2] and plants [3], whereas shorter-chain $\left(\mathrm{C}_{55-85}\right)$ compounds are found in lower eukaryotes and in cell-surface glycoprotein-producing bacteria as, for example, Halobacterium sp. [4] and Bacillus sp. [5]. The major biological function of dolichyl phosphates is to serve as obligatory intermediates in the process of protein glycosylation [6]. Dolichyl phosphates may exist in a form covalently linked to a protein [7]; however, the biological significance of this observation is not known.

$\alpha$-Unsaturated polyprenyl phosphates are found in bacteria, where they function as precursors for the biosynthesis of cell-wall polymers. The most common form of bacterial polyprenyl phosphates is a $\mathrm{C}_{55^{-}}$ undecaprenyl phosphate [8]. In mycobacteria, arabinosylated and ribosylated forms of a shorter $\mathrm{C}_{50^{-}}$ decaprenyl phosphate were described $[9,10]$ and the 


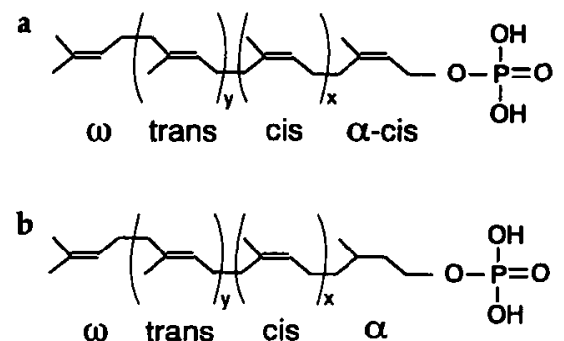

$\omega$ trans cis $\alpha$

Scheme I. The structure of naturally occurring polyprenyl (a) and dolichyl (b) phosphates. The cis/trans geometry of internal isoprene units (where $y$ is usually 2 and $x$ may vary from 7 to about 20, depending on the source), as well as the position of $\alpha$ and $\omega$-isoprene residues are shown.

decaprenyl chain was shown to contain only one internal trans-isoprene residue [9] in contrast to other natural polyprenyl and dolichyl phosphates, which are known to contain two internal trans-isoprene units (Scheme I) [1]. A few physicochemical studies demonstrated that dolichyl and polyprenyl phosphates have a destabilizing effect on membrane structure [11], which suggests another possible physiological role of polyisoprenyl phosphates in the activity and function of biological membranes.

Given the key role of polyprenyl and dolichyl phosphates in nature and the fact that, in some organisms $[5,3]$, both types of polyisoprenyl phosphates seem to operate (for example, Bacillus sp. utilizes a $\mathrm{C}_{55^{-}}$ undecaprenyl-P for the biosynthesis of cell-wall polysaccharides and a $\mathrm{C}_{55}$-dolichyl-P for the biosynthesis of a glycoprotein), it is important to develop new sensitive and informative methods for the structural determination of these compounds. Until now, several different physicochemical and degradative approaches have been applied for the structural analysis of polyisoprenyl phosphates. Thus, to confirm the polyisoprenoid nature of a lipid, methods such as infrared spectroscopy, nuclear magnetic resonance and electron impact mass spectrometry have been used [12]. All the three methods are quite insensitive, however. Additionally, the electron impact mass spectrometry requires a dephosphorylation step prior to analysis and this may cause important losses of dolichyl phosphate samples, which are resistant to hydrolytic treatments. Although the problem can be overcome partially by the use of desorption electron impact ionization mass spectrometry for the analysis of intact polyisoprenyl phosphates [13], the electron impact mass spectra of polyisoprenoid compounds are difficult to interpret because of extensive rearrangement reactions.

Evidence for the presence of a phosphorylated derivative of polyisoprenol can be obtained by nuclear magnetic resonance and fast-atom bombardment mass spectrometry. In spite of its good sensitivity, the only useful information provided by the latter method [14] is the molecular weight of a compound, because of a lack of sufficient fragmentation. Some structurally relevant fragmentations could be observed, however, in the fast-atom bombardment tandem mass spectrometry of short-chain isoprenoid pyrophosphates [15] and of glycosyl esters of polyisoprenyl phosphates $[9,10,13,16]$. The latter approach proved to be useful for the determination of the anomeric configuration of polyisoprenyl-phospho-sugars [16]. Finally, the presence of an $\alpha$-saturated isoprene unit in a dolichyl phosphate molecule can be deduced by infrared spectroscopy, ozonolysis, acid hydrolysis, nuclear magnetic resonance [12], and by mass spectrometric techniques, such as fast-atom bombardment [14,17] and plasma desorption mass spectrometry [5], on the basis of a 2-u shift in comparison with a corresponding unsaturated polyprenyl phosphate.

Our preliminary report [13] showed that, in negative-ion desorption chemical ionization mass spectrometry (DCI-MS) of the mycobacterial $\mathrm{C}_{50}$-decaprenyl phosphate, a dephosphorylated $\left[\mathrm{M}-\mathrm{H}_{3} \mathrm{PO}_{4}-\mathrm{H}\right]^{-}$ ion was produced which, in tandem mass spectrometry, gave series of intense fragment ions $68 \mathrm{u}$ apart, indicative of the polyisoprenoid nature of a phospholipid. In the present work, by using chemically defined unlabeled and deuterated polyprenyl and dolichyl phosphate standards, we demonstrate that fragmentations of a polyisoprenyl-P chain in desorption chemical ionization tandem mass spectrometry (DCI-MS/MS) proceed from both ends ( $\alpha$ and $\omega$ ) of the lipid moiety and take place at both allylic and vinylic sites. We show also that the DCI-MS/MS pattern of dolichyl phosphates differs from that of polyprenyl phosphates and, consequently, that it can be utilized to determine the presence of an $\alpha$-saturation in a polyisoprenyl-P molecule. A possible mechanism of fragmentation of polyprenyl phosphates is discussed.

\section{Experimental}

\section{Preparation of Polyisoprenyl Phosphates}

Polyprenols were isolated from leaves of Rhus typhina and Laurus nobilis as previously described [18, 19]. Dolichols were obtained by selective hydrogenation of the $\alpha$-isoprene residue of the corresponding polyprenols [20]. Labeling of undecaprenol at the C-1 position with deuterium was performed by oxidization of the isoprenoid alcohol with chromium trioxide-pyridine complex, followed by reduction of the obtained aldehyde with sodium borodeuteride, in accordance with the procedure of Keenan and Kruczek [21]. Polyprenyl and dolichyl monophosphates were prepared by chemical phosphorylation [22, 23].

\section{Proton-NMR Spectroscopy}

${ }^{1} \mathrm{H}$-NMR spectra of $10-\mathrm{mg} / \mathrm{mL}$ solutions of polyisoprenyl phosphates in a $\left.\mathrm{C}\left[{ }^{2} \mathrm{H}\right] \mathrm{Cl}_{3}-\mathrm{C}^{2} \mathrm{H}\right]_{3} \mathrm{O}\left[{ }^{2} \mathrm{H}\right]$ mixture $(2: 1 \mathrm{v} / \mathrm{v})$ were recorded on a Bruker $500-\mathrm{MHz}$ instrument. Chemical shifts are reported with respect to internal tetramethylsilane. 


\section{Mass Spectrometry}

Fast-atom bombardment (FAB) mass spectrometry was performed on a Finnigan-MAT (San Jose, CA) TSQ 70 triple quadrupole mass spectrometer with an Ion Tech (Middlesex, UK) FAB gun operated at $7 \mathrm{keV}$ and $1 \mathrm{~mA}$ with xenon as the target gas. Polyisoprenyl phosphates were dissolved in chloroform-methanol (2:1) to a concentration of $1 \mathrm{mg} / \mathrm{mL}$ and $1 \mu \mathrm{L}$ of the solution was applied to a thioglycerol matrix. For purposes of desorption chemical ionization, $1 \mu \mathrm{L}$ of the solution was deposited on a rhenium wire and the solvent was evaporated. The wire was then introduced into the TSQ 70 ion source and heated from 40 to $1100{ }^{\circ} \mathrm{C}$ at a rate of $\sim 450{ }^{\circ} \mathrm{C} / \mathrm{min}$ in the chemical ionization plasma composed of a mixture of $\mathrm{CH}_{4}$ and $\mathrm{N}_{2} \mathrm{O}(3: 1)$. Polyisoprenyl phosphates desorbed usually at about $380^{\circ} \mathrm{C}$. In the tandem mass spectrometry experiments, the collision offset voltage was $6 \mathrm{~V}$ and the pressure of the target gas (xenon) was 0.6 mtorr. In all experiments the scan time was $1 \mathrm{~s}$ and each recorded spectrum represented an average of approximately 10 significant spectra.

\section{Results and Discussion}

Fast-Atom Bombardment Mass Spectrometry and Proton-NMR Characterization of Semisynthetic Polyisoprenyl Phosphates

The molecular weights of the semisynthetic polyisoprenyl phosphates were determined by using negativeion fast-atom bombardment mass spectrometry (FABMS). For unlabeled $\mathrm{C}_{55}$-undecaprenyl and $\mathrm{C}_{55}$-dolichyl phosphates, an abundant signal derived from the deprotonated free acid molecule $[\mathrm{M}-\mathrm{H}]^{-}$was observed (relative intensity, 100\%) at $\mathrm{m} / \mathrm{z} 845$ and 847 , respectively (Table 1 ). In the case of $\left[1{ }^{2} \mathrm{H}\right]$ undecaprenyl phosphate labeled with deuterium at the $\mathrm{C}-1$ position, the signal of the deprotonated free acid molecule was shifted by $1 \mathrm{u}(\mathrm{m} / \mathrm{z}$ 846) in comparison to the unlabeled undecaprenyl-P, which indicates that the reduction of the corresponding aldehyde with sodium borodeuteride went to completion (see Experimental and Table 1).
The negative-ion FAB mass spectra of $\mathrm{C}_{55}$-polyisoprenyl phosphates also showed the presence of a series of fragment ions (for example, for the undecaprenyl phosphate at $m / z 775,707,639,571,503,435,367,299$, and 231) resulting from the loss of one or more isoprene residue and a hydrogen atom from the isoprenoid chain (not shown). It is significant that this series was shifted by $1 \mathrm{u}$ in the case of deuteriumlabeled $\left[1-{ }^{2} \mathrm{H}\right]$ undecaprenyl-P (at $m / z \quad 776,708$, etc.; not shown), which indicates that fragmentation proceeded from the $\omega$ end of the chain probably through a charge-remote fragmentation mechanism(s) [24]. Similar charge-remote fragmentations of the polyisoprenoid chain were observed in the fast-atom bombardment mass spectra of the arabinosyl- and ribosyl-monophosphodecaprenols isolated from a mycobacterium $[9,10]$. Because signals derived from chargeremote fragmentations of polyisoprenyl-P derivatives are very weak (relative intensities of ions of $\mathrm{m} / \mathrm{z}>400$ are $10 \%$ or lower), the FAB-MS pattern of a polyisoprenyl-P hardly could be used for confirmation of the polyisoprenoid nature of a compound, especially in biological samples in which impurities may give substantial chemical noise signal. Furthermore, the [M $\mathrm{H}]^{-}$deprotonated molecule of polyisoprenyl phosphates produces no fragments in low collision energy fast-atom bombardment tandem mass spectrometry, which fact points again to the limitations of the fastatom bombardment techniques in the structural determination of polyisoprenyl phosphates.

Further structural information on the semisynthetic polyprenyl phosphates was obtained by ${ }^{\mathrm{i}} \mathrm{H}-\mathrm{NMR}$ spectroscopy (Table 2). Integration of the methyl proton signals of the undecaprenyl phosphate revealed that four isoprene methyl groups of the undecaprenyl phosphate (one from the $\omega$ residue and three others) are in trans configuration and eight isoprene methyl groups (one from the $\omega$ residue, one from the $\alpha$ residue, and six others) are in cis configuration [19]. Since isoprene trans residues are known to be located at the $\omega$ end of a polyisoprenol molccule [1], we conclude that all the $\mathrm{C}_{55}$-undecaprenyl-based derivatives (undecaprenyl and dolichyl phosphates) used in this study contain three internal trans-isoprene groups at the $\omega$ end of the isoprenoid chain. Comparison

Table 1. Negative-ion fast atom bombardment mass spectrometry of unlabeled and deuterated semisynthetic $C_{55}$-polyisoprenyl phosphates

\begin{tabular}{|c|c|c|c|}
\hline \multirow[b]{2}{*}{ Ion } & \multicolumn{3}{|c|}{ Relative abundance (\%) } \\
\hline & $\begin{array}{c}\text { Undecaprenyl-P } \\
\text { (MW' 846) }\end{array}$ & $\begin{array}{c}{\left[1-{ }^{2} H\right] \text { Undecaprenyl-P }} \\
\text { (MW 847) }\end{array}$ & $\begin{array}{l}\mathrm{C}_{55}-\text { Dolichyl-P } \\
\text { (MW 848) }\end{array}$ \\
\hline$m / 2845.7$ & 100 & - & - \\
\hline $\mathrm{m} / \mathrm{z} 846.7$ & 46 & 100 & - \\
\hline $\mathrm{m} / \mathrm{z} 847.7$ & 23 & 47 & 100 \\
\hline$m / z 848.8$ & - & 19 & 57 \\
\hline $\mathrm{m} / \mathrm{z} 849.8$ & 一 & - & 21 \\
\hline
\end{tabular}

${ }^{a} \mathrm{MW}$ is molecular weight. 
Table 2. ' $\mathrm{H}$-NMR characterization of the unlabeled and deuterium-labeled semisynthetic undecaprenyl phosphates

\begin{tabular}{|c|c|c|c|}
\hline \multirow{2}{*}{$\begin{array}{l}\text { Chemical shift } \\
\text { (ppm) }\end{array}$} & \multirow[b]{2}{*}{ Assignment } & \multicolumn{2}{|c|}{ Relative areas ${ }^{a}$} \\
\hline & & Undecaprenyl-P & {$\left[1-{ }^{2} \mathrm{H}\right]$ Undecaprenyl-P } \\
\hline 1.560 & $\mathrm{CH}_{3}$-trans & & \\
\hline 1.573 & $\mathrm{CH}_{3}-\operatorname{trans}(\omega)$ & $12.5(12)$ & $13.0(12)$ \\
\hline 1.637 & $\mathrm{CH}_{3}-$ cis and $\mathrm{CH}_{3}-\operatorname{cis}(\omega)$ & $25.0(24)$ & $26.8(24)$ \\
\hline 1.690 & $\mathrm{C}_{\mathrm{H}_{3}}-\operatorname{cis}(\alpha)$ & & \\
\hline 2.002 & $-\mathrm{CH}_{2}-\mathrm{C}=$ & $b$ & b \\
\hline $4.350,4.364,4.376$ & $\begin{array}{l}=\mathrm{CH}-\mathrm{CH}_{2}-\mathrm{O}- \\
\left.=\mathrm{CH}-\mathrm{CH}^{2}{ }^{2} \mathrm{H}\right]-\mathrm{O}-\end{array}$ & $1.98(2)$ & $1.03(1)$ \\
\hline 5.091 & $-\stackrel{\mathrm{C}}{\mathrm{C}}=\mathrm{C} \underline{\mathrm{H}}-$ & $11.20(11)$ & $11.77(11)$ \\
\hline $5.338,5.350,5.365$ & $=\mathrm{C} \underline{\mathrm{H}}-\mathrm{CH}_{2}-\mathrm{O}-$ & $1.03(1)$ & - \\
\hline $5.340,5.353$ & $=\mathrm{CH}-\mathrm{CH}\left[{ }^{2} \mathrm{H}\right]-\mathrm{O}-$ & - & $1.04(1)$ \\
\hline
\end{tabular}

"Theoretical values are given in parentheses.

${ }^{b}$ Not determined.

of the ${ }^{1} \mathrm{H}-\mathrm{NMR}$ spectra of the undecaprenyl and deuterium-labeled $\left[1-{ }^{2} \mathrm{H}\right]$ undecaprenyl phosphates confirmed the presence and location of the deuterium atom in the latter derivative (Table 2). In particular, the signal at $4.364 \mathrm{ppm}$ that corresponds to the methylene protons at the $\mathrm{C}-1$ position of the $\alpha$-isoprene residue $\left(=\mathrm{CH}-\mathrm{C} \underline{\mathrm{H}}\left[{ }^{2} \mathrm{H}\right]-\mathrm{O}-\right)$ integrated for only one proton of the deuterated derivative in contrast to two protons in the unlabeled undecaprenyl-P. Consequently, the multiplicity of the signal at $5.350 \mathrm{ppm}$ derived from the adjacent methine proton of the $\alpha$ residue $\left(=\mathrm{CH}-\mathrm{CH}\left[{ }^{2} \mathrm{H}\right]-\mathrm{O}-\right)$ changed from a triplet (for the unlabeled undecaprenyl-P) to a doublet in the proton-NMR spectrum of the deuterium-labeled [1${ }^{2} \mathrm{H}$ ] undecaprenyl phosphate (Table 2).

\section{Negative-Ion Desorption Chemical Ionization Mass Spectrometry of Polyisoprenyl Phosphates}

The negative-ion desorption chemical ionization spectrum of $\mathrm{C}_{55}$-undecaprenyl phosphate shows the presence of fragment ions at $m / z 779,765$, and 747, derived from independent losses of a part of or the whole phosphoric acid molecule, and corresponding to [M $\mathrm{H}_{3} \mathrm{PO}_{2}-\mathrm{H}^{-}$, [M $\left.-\mathrm{HPO}_{3}-\mathrm{H}\right]^{-}$, and $\left[\mathrm{M}-\mathrm{H}_{3} \mathrm{PO}_{4}\right.$ $-\mathrm{H}]^{-}$, respectively (Figure 1a). No signal of the deprotonated undecaprenyl phosphate molecule $[\mathrm{M}-\mathrm{H}]^{-}$ could be observed in the DCI-MS spectrum. Analogous DCI-MS fragments were obtained for all the other polyprenyl and dolichyl phosphates tested, the polyisoprenoid chain of which length ranged from $7\left(C_{35}\right)$ to $20\left(C_{100}\right)$ isoprene units (not shown). In DCI-MS, the $\left[1-{ }^{2} \mathrm{H}\right]$ undecaprenyl phosphate labeled specifically with deuterium at the $\mathrm{C}-1$ position produced an intense $\left[\mathrm{M}-\mathrm{H}_{3} \mathrm{PO}_{4}-\mathrm{H}^{-}\right.$ion at $\mathrm{m} / \mathrm{z} 748$ (relative intensity $100 \%$ ), thus indicating that the proton sub- traction does not occur at the C-1 position. It is worth noting that the carbon-1 site of the deuterated [1$\left.{ }^{2} \mathrm{H}\right]$ undecaprenyl phosphate represents a new chirality center and that the chemically synthesized compound can be expected to consist of a mixture of $(R, S)$ isomers.

In contrast to polyisoprenyl phosphates, free polyisoprenoid alcohols produce an abundant $[\mathrm{M}-\mathrm{H}]^{-}$ signal of the deprotonated molecule by chemical ionization [17]. However, low-energy collision-induced dissociation spectra of the $[\mathrm{M}-\mathrm{H}]^{-}$deprotonated molecule of polyisoprenyl alcohols produced by desorption chemical ionization are very complex and, therefore, unsuitable for the structural analysis of polyisoprenoid chains.

Tandem Mass Spectrometry of the $\left[\mathrm{M}-\mathrm{H}_{3} \mathrm{PO}_{4}-\right.$ $\mathrm{HJ}^{-}$- Ion of Polyisoprenyl Phosphates

The product ion spectra of the $\left[\mathrm{M}-\mathrm{H}_{3} \mathrm{PO}_{4}-\mathrm{H}\right]^{-}$ fragment of polyisoprenyl phosphates reveal the presence of an intense series of ions $68 \mathrm{u}$ apart at $\mathrm{m} / \mathrm{z} 475$, 407, 339, 271 and at $m / z$ 477, 409, 341, 273 for undecaprenyl and $C_{55}$-dolichyl phosphates, respectively (Figure $1 b$ and $d$ ). These fragments arise from the allylic cleavages of a polyisoprenoid chain. By a proper selection of the collision energy, intense fragments can be obtained except at low mass; the smallest observable ion (at $m / z$ 189) would correspond to a fragment that contains three isoprene residues minus $14 \mathrm{u}$.

Examination of the tandem mass spectrum of the $\left[\mathrm{M}-\mathrm{H}_{3} \mathrm{PO}_{4}-\mathrm{H}\right]^{-}$fragment of the deuterated [1$\left.{ }^{2} \mathrm{H}\right]$ undecaprenyl phosphate $(m / z$ 748) demonstrated that, for this derivative, the above-mentioned series of ions is shifted by $1 \mathbf{u}$ and observed at $m / z 476,408$, 340 , and 272 , respectively, which indicates that the 
a

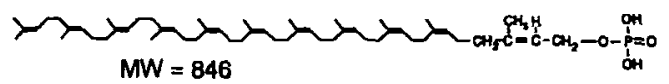

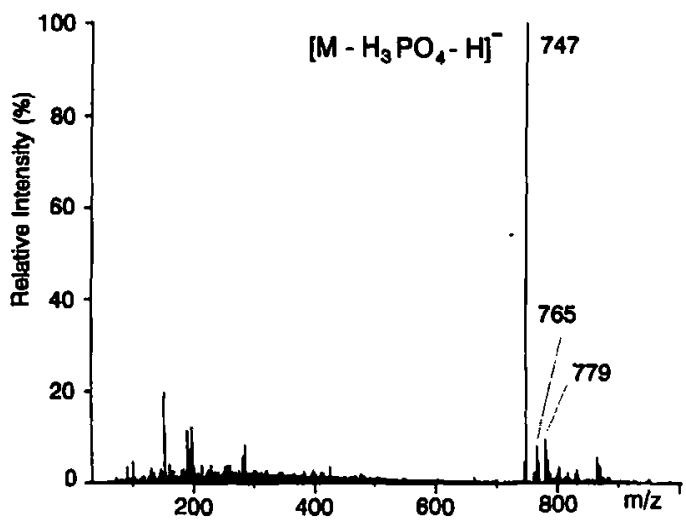

C
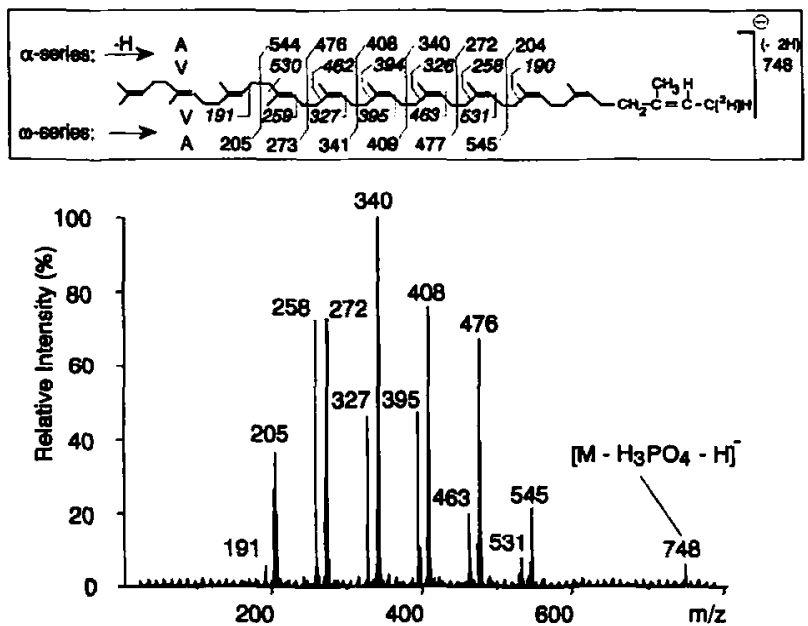

b
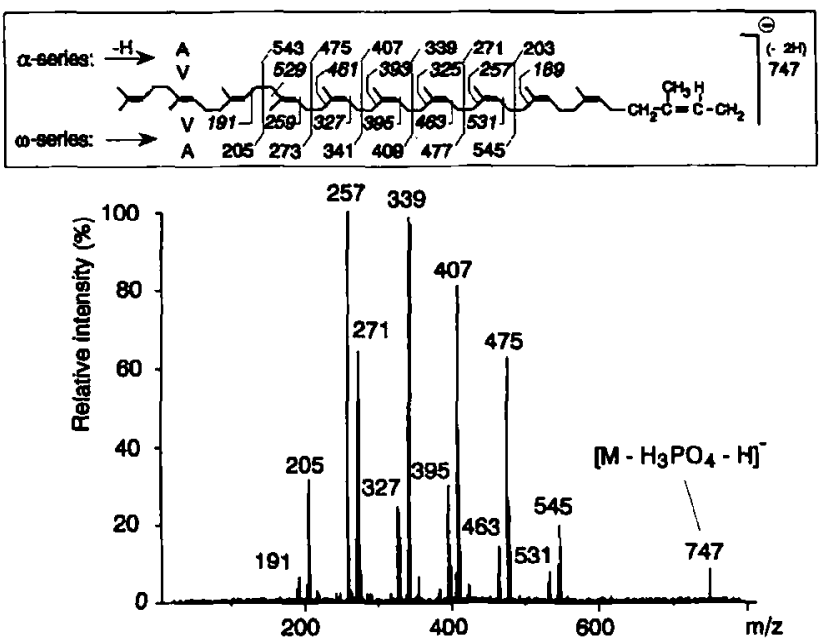

d
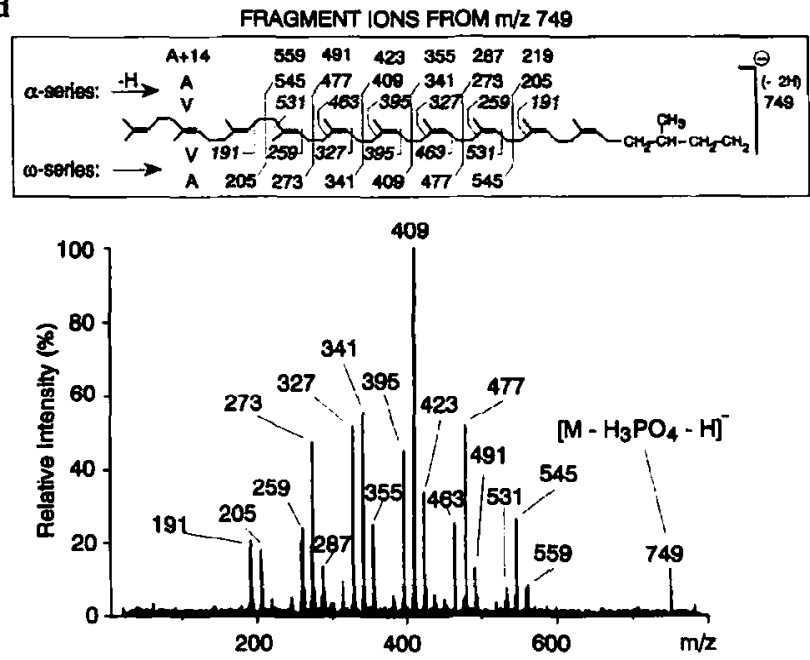

Figure 1. Negative-ion desorption chemical ionization tandem mass spectrometry of $\mathrm{C}_{55}$-polyisoprenyl phosphates. (a) The negative-ion DCI spectrum of undecaprenyl phosphate. The product ion spectrum of the $\left[\mathrm{M}-\mathrm{H}_{3} \mathrm{PO}_{4}-\mathrm{H}\right]^{-}$fragment derived from (b) undecaprenyl phosphate [nominal mass 747, observed mass 747.9, monoisotopic mass 747.7 (Hsu, L. Anal. Chem. 1984, 56, 1356-1361)], (c) [1- $\left.{ }^{2} \mathrm{H}\right]$ undecaprenyl phosphate (nominal mass 748 , observed mass 748.9 , monoisotopic mass 748.7), and (d) $\mathrm{C}_{55}$-dolichyl phosphate (nominal mass 749 , observed mass 749.9 , monoisotopic mass 749.7). A denotes allylic cleavage; $V$ denotes vinylic cleavage.

deuterium atom of the $\alpha$-isoprene residue is preserved in all these fragments (Figure 1c). Accordingly, this series of ions can be described as $\alpha A$ series ( $A$, for allylic cleavage). The $\alpha \mathrm{A}$ series of product ions of the $\left[\mathrm{M}-\mathrm{H}_{3} \mathrm{PO}_{4}-\mathrm{H}\right]^{-}$polyisoprenyl-P fragment is accompanied by an analogous series of fragments that are $14 \mathrm{u}$ smaller and also contain the $\alpha$ end, but arise from vinylic cleavages of a polyisoprenoid chain $(\alpha \mathrm{V}$ series). The $\alpha \mathrm{V}$ series is much less intense than the $\alpha \mathrm{A}$ series with the exception of a four isoprene units-derived fragment at $\mathrm{m} / \mathrm{z} 257$ and 258 for the unlabeled (Figure $1 \mathrm{~b}$ ) and deuterated (Figure 1c) undecaprenyl-P, respectively.

Another series of fragments can be distinguished in the product ion mass spectra of the $\left[\mathrm{M}-\mathrm{H}_{3} \mathrm{PO}_{4}-\right.$ $\mathrm{H}]^{-}$ion of polyisoprenyl phosphates at $\mathrm{m} / z$ 531,463, 395 and 327 (Figure 1b-d). These signals are not in- fluenced by the presence of deuterium or a saturation of the $\alpha$-isoprene residue and, therefore, they can be ascribed to fragments containing an intact $\omega$ end and resulting from vinylic cleavages of a polyisoprenoid chain ( $\omega \mathrm{V}$ series). In addition to the $\omega \mathrm{V}$ series, fragments that contain the $\omega$-isoprene unit but are derived from allylic cleavages of a polyisoprenoid chain (at $m / z 545,477,409,341,273$ and 205) are clearly seen (Figure $1 \mathrm{~b}-\mathrm{d}$ ); they form the $\omega \mathrm{A}$ series.

The product ion spectrum of the $\left[\mathrm{M}-\mathrm{H}_{3} \mathrm{PO}_{4}-\right.$ $\mathrm{H}]^{-}$fragment of $\mathrm{C}_{55}$-dolichyl phosphate demonstrates, however, a distinct feature, namely, the presence of an additional series of ions $(A+14) 14 u$ larger than fragments resulting from allylic (A) cleavages of an $\alpha$-saturated polyisoprenoid chain (Figure 1d). Since in the case of dolichyl phosphates, allylic fragments of the $\alpha$ series are observed at the same mass-to-charge 
ratio value as vinylic fragments of the $\omega$ series, it is impossible as yet to determine to which series ( $\alpha$ or $\omega$ ) the $(\mathrm{A}+14)$ ions belong. Nevertheless, the described pattern is characteristic for dolichyl phosphates and can be used to distinguish between fully unsaturated and $\alpha$-saturated polyisoprenyl phosphates, as shown in Figure 2 for the $\mathrm{C}_{90}$-octadecaprenyl phosphate (Figure $2 \mathrm{a})$ and 2,3-dihydro-octadecaprenyl ( $\mathrm{C}_{90}$-dolichyl) phosphate (Figure 2b).

The polyisoprenoid anion obtained by desorption chemical ionization of polyisoprenyl phosphates contains no stable charge location and, consequently, it is expected that the observed fragmentations would represent charge-driven reactions (Scheme II). Our results show that all the fragments are derived from allylic or vinylic cleavages from both ends of the polyisoprenoid chain and that cleavage across double bonds does not occur in tandem mass spectrometry of the [M $\left.\mathrm{H}_{3} \mathrm{PO}_{4}-\mathrm{H}\right]^{-}$ion of polyisoprenyl phosphates. As depicted in Scheme II, abstraction of a proton from either the methyl or one of the two methylene groups of an isoprene unit yields an allylic anion. Ionization of the methyl group $(x)$ may occur because this group con-

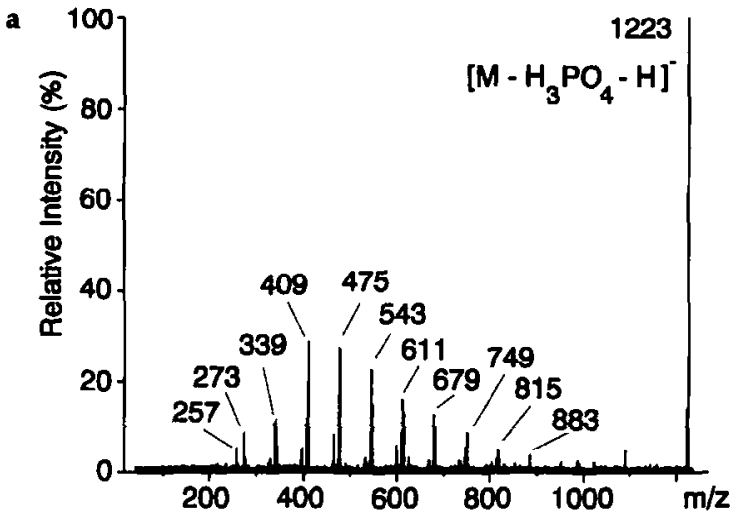

b

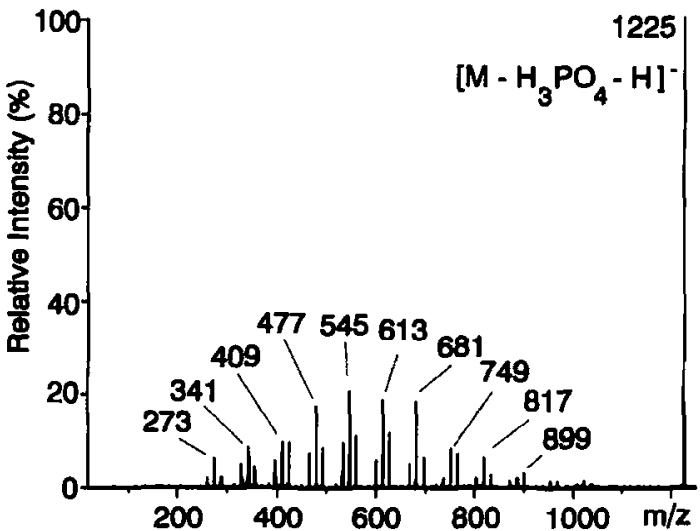

Figure 2. Negative-ion desorption chemical ionization tandem mass spectrometry of $\mathrm{C}_{90}$-polyisoprenyl phosphates. The product ion spectrum of the $\left[\mathrm{M}-\mathrm{H}_{3} \mathrm{PO}_{4}-\mathrm{H}\right]^{-}$fragment derived from (a) octadecaprenyl phosphate [nominal mass 1223; observed mass 1223.8, monoisotopic mass 1224.1 (Hsu, L. Anal. Chem. 1984, 56, 1356-1361)] and (b) 2,3-dihydro-octadecaprenyl ( $\mathrm{C}_{90}$-dolichyl) phosphate (nominal mass 1225, observed mass 1226.1, monoisotopic mass 1226.1).

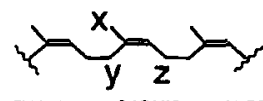

THPEE POTENTIAL ALLYUIC IONISATION CENTERS: $x, y, z$
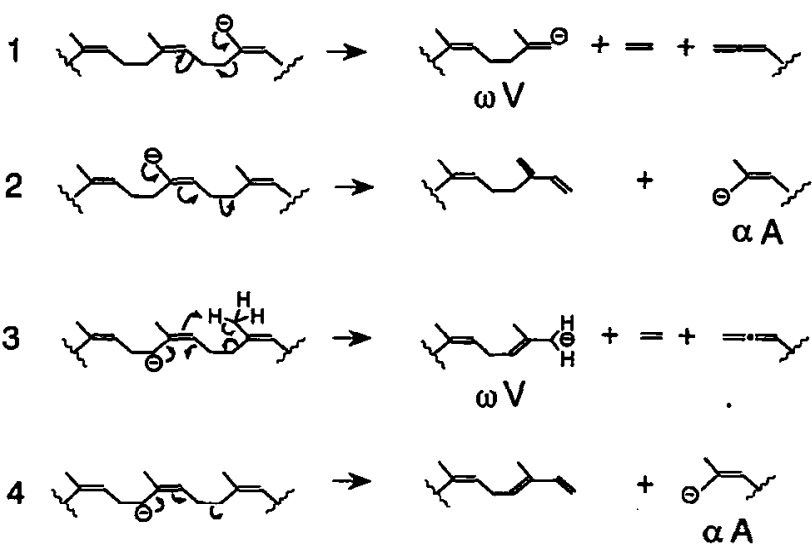

Scheme II. Possible mechanisms of fragmentation of a polyisoprenoid chain in the negative-ion desorption chemical ionization tandem mass spectrometry of polyprenyl phosphates. If ionization occurs at the methyl group of an isoprene unit (ionization center $x$; reactions 1 and 2) or at the methylene group (ionization center $y$; reactions 3 and 4), two series of fragments are produced, $\alpha \mathrm{A}$ and $\omega \mathrm{V}$, where $\alpha$ and $\omega$ refers to the fragments that contain $\alpha$ - and $\omega$-isoprene units, whereas $A$ and $V$ refer to allylic and vinylic cleavages, respectively.

tains the highest number of hydrogen atoms and is more acidic in comparison to the two methylene groups of an isoprene residue [25,26]. The resulting anion could give the $\omega \mathrm{V}$ and $\alpha \mathrm{A}$ series of fragments (Scheme II, reactions 1 and 2, respectively), which are, indeed, the most abundant fragments observed experimentally. Alternatively, if a methylene group is ionized at the $(y)$ position, a more stabilized anion [27] could result from a rearrangement and give the same $(\omega \mathrm{V}$ and $\alpha A$ ) series of fragments (Scheme $\Pi$, reactions 3 and 4). Finally, generation of the $\omega \mathrm{A}$ and $\alpha \mathrm{V}$ series of fragments (not shown) could be expected if ionization occurs at the $(z)$ position (Scheme II). However, further isotopic studies would be necessary to explain the mechanism of formation of the $(A+14)$ series in the desorption chemical ionization tandem mass spectrometry of dolichyl phosphates.

\section{Conclusions}

Our results show that negative-ion desorption chemical ionization tandem mass spectrometry offers an alternative approach for the analysis of polyisoprenyl phosphates. The method is sensitive (polyisoprenyl-P can be analyzed at the nanomole level) and provides important structural information about the chain length, the phosphorylation state, and the presence of $\alpha$ saturation and, possibly, other modifications within a polyisoprenoid chain.

Polyprenyl and dolichyl phosphates of different chain length (from $C_{35}$ to $C_{100}$ ) produce, in the nega- 
tive-ion desorption chemical ionization, an intense [M $\left.-\mathrm{H}_{3} \mathrm{PO}_{4}-\mathrm{H}\right]^{-}$ion and two less abundant [M $\left.\mathrm{H}_{3} \mathrm{PO}_{2}-\mathrm{H}\right]^{-}$and $\left[\mathrm{M}-\mathrm{HPO}_{3}-\mathrm{H}\right]^{-}$fragments. Collision-induced dissociation of the $\left[\mathrm{M}-\mathrm{H}_{3} \mathrm{PO}_{4}-\mathrm{H}\right]^{-}$ fragment results in generation of series of product ions that are $68 \mathrm{u}$ apart, indicative of the polyisoprenoid nature of a compound. By using deuterated and $\alpha-$ saturated polyisoprenyl phosphates, it was shown that fragmentations proceed from both ends of a polyisoprenoid chain, thus giving rise to two ( $\alpha$ and $\omega$ ) series of product ions with preserved $\alpha$ - and w-isoprene unit, respectively. Cleavages of a polyisoprenoid chain in the tandem mass spectrometry of the $\left[\mathrm{M}-\mathrm{H}_{3} \mathrm{PO}_{4}\right.$ $-\mathrm{H}]^{-}$ion may occur at either allylic or vinylic sites with respect to a double bond and, consequently, two subseries (A and V) can be distinguished within the $\alpha$ and $\omega$ series of fragments. For polyprenyl phosphates, the four series of fragments can be described by the following formulas: $\alpha \mathrm{A}=[n \times 68-1], \alpha \mathrm{V}=[\alpha \mathrm{A}-$ $14]=[n \times 68-15], \quad \omega \mathrm{A}=[69+(n-1) \times 68]=[n$ $\times 68-1], \quad \omega \mathrm{V}=[\omega A-14]=[69+(n-1) \times 68-$ $14]=[n \times 68-13]$, where $n$ is the number of isoprene units and $3 \leq n$ is less than the total number of isoprene residues within a polyisoprenoid chain. For dolichyl phosphates, the $\alpha$-series undergo a 2-u shift because of the presence of an $\alpha$ saturation; the corresponding formulas are $\alpha \mathrm{A}=[70+(n-1) \times 68-1]$ $=[n \times 68+1]$ and $\alpha \mathrm{V}=[\alpha \mathrm{A}-14]=[n \times 68-13]$. Therefore, in the case of dolichyl phosphates, the masses of the two $\alpha$ series of fragments, $\alpha \mathrm{A}$ and $\alpha \mathrm{V}$, coincide with those of the $\omega \mathrm{A}$ and $\omega \mathrm{V}$ series, respectively.

Additionally, the product ion spectra of the [M $\left.\mathrm{H}_{3} \mathrm{PO}_{4}-\mathrm{H}\right]^{-}$ion of $\alpha$-saturated dolichyl phosphates show a distinct pattern due to the presence of another series of ions $(A+14) 14 u$ larger than fragments arising from the allylic cleavages of an $\alpha$-saturated polyisoprenoid chain, and this feature can be used for the differentiation between polyprenyl and dolichyl phosphates of the same chain length.

Further studies on isotopically labeled dolichyl phosphates and other polyisoprenyl phosphates that contain modifications within a polyisoprenoid chain will be necessary to elucidate specific fragmentation pathways of these compounds in desorption chemical ionization tandem mass spectrometry.

\section{Acknowledgments}

This work was supported by a grant (to B.A.W.) from the World Health Organization Special Programme for Research and Training in Tropical Diseases (project 920454) and a grant (to E.d.H.) from the Fonds National pour la Recherche Scientifique, Belgium. We thank Dr. Claudette Moreaux for NMR measurements and Dr. Vincent Stroobant for scientific discussion.

\section{References}

1. Hemming, F. W. In Glycolipids; Wiegandt, H., Ed.; Elsevier Science: Amsterdam, 1985; pp 261-305.

2. Chojnacki, T.; Dallner, G. Biochem. J. 1988, 251, 1-9.

3. Pont Lezica, R.; Daleo, G. R.; Dey, P. M. Adv. Carbohydr. Chem. Biochem. 1986, 44, 341-385.

4. Lechner, J.; Wieland, F.; Sumper, M. J. Biol. Chem. 1985, 260, 860-866.

5. Hartmann, E.; Messner, P.; Allmeier, G.; König, H. J. Bacteriol. 1993, 175, 4515-4519.

6. Schwarz, R. T.; Datema, R. Adv. Carbohydr. Chem. Biochem. 1982, 40, 287-379.

7. Thelin, A.; Löw, P.; Chojnacki, T.; Dallner, G. Eur. J. Biochem. 1991, 195, 755-761.

8. Shibaev, V. N. Adv. Carbohydr. Chem. Biochem. 1986, 44, 277-339.

9. Wolucka, B. A.; McNeil, M. R.; de Hoffmann, E.; Chojnacki, T.; Brennan, P. J. J. Biol. Chem. 1994, 269, 23328-23335.

10. Wolucka, B. A.; de Hoffmann, E. J. Biol. Chem. 1995, 270, 20151-20155.

11. Schutzbach, J. S.; Jensen, J. W. Chem. Phys. Lipids 1989, 51, 213-218.

12. Hemming, F. W. Biochem. Cell Biol. 1992, 70, 377-381.

13. Wolucka, B. A., de Hoffmann, E. Actn Biochim. Pol. 1994, 41, 345-349.

14. Hermansson, K.; Jansson, P.-E.; Löw, P.; Dallner, G.; Swiezewska, E.; Chojnacki, T. Biol. Mass Spectrom. 1992, 21, 548-553.

15. Kitaoka, M.; Nagaki, H.; Kinoshita, T.; Kurabayashi, M.; Koyama, T,; Ogura, K. Anal. Biochem. 1990, 185, 182-186.

16. Wolucka, B. A.; Rush, J. S.; Waechter, C. J.; de Hoffmann, E. J. Am. Soc. Mass Spectrom. 1996, 7.

17. Löw, P.; Dallner, G.; Mayor, S.; Cohen, S.; Chait, B. T.; Menon, A. K. J. Biol. Chem. 1991, 266, 19250-19257.

18. Chojnacki, T.; Jankowski, W.; Mankowski, T.; Sasak, W. Anal. Biochem. 1975, 69, 114-119.

19. Chojnacki, T.; Swiezewska, E.; Vogtman, T. Chimica Scriptn 1987, 27, 209-214.

20. Mankowski, T.; Jankowski, W.; Chojnacki, T.; Franke, P. Biochemistry 1976, 15, 2125-2130.

21. Keenan, R. W.; Kruczek, M. Anal. Biochem. 1975, 69, 504-509.

22. Cramer, F.; Böhm, W. Angew. Chem. 1959, 71, 775.

23. Danilov, L. L.; Chojnacki, T. FEBS Lett. 1981, 131, 310-312.

24. Adams, J. Mass Spectrom. Rev. 1990, 9, 141-186.

25. Bartmess, J. E.; Scott, J. A.; McIver, R. T., Jr. J. Am. Chem. Soc. 1979, 101, 6046-6056.

26. Lias, S. G.; Bartmess, J. E.; Liebman, J. F.; Holmes, J. L.; Levin, R. D.; Mallard, W. G. J. Phys. Chem. Ref. Data 1988, 17, Suppl. 1, 686.

27. Froelicher, S. W.; Freiser, B. S.; Squires, R. R. J. Am. Chem. Soc. 1986, 108, 2853-2862.

28. Hsu, L. Anal. Chem. 1984, 56, 1356-1361. 